\title{
Creative Coding as Compost(ing)
}

\author{
Tomi Slotte Dufva
}

\section{INTRODUCTION}

What would happen if one day, all of a sudden, by some mysterious force, all the digital devices, equipment, and machinery would burst into flames, fry, all at once, and we would be left to survive without any of the devices, infrastructures, and machinery most of us have grown accustomed to having? This is a question Hayles (2019) recently raised, not attempting to posit dystopian panic but instead to earnestly inspect the roles various digital processes have on everyday lives of most of us. In less than a century, the digital revolution has substituted or completely displaced earlier technologies. Digital has become so routine that most of us rarely wonder about the fact that a little device in our pocket can tell us a route to the nearest cafe, warn about traffic hazards, and maintain a video call to a friend in another part of the world, all at the same time. Berry calls this a post-digital world; a world that is so entirely saturated by digital devices and processes, that not using them is a deviation from the norm (Berry, 2016, p. 3).

A famous meme announces that "You are not a real hipster - until you take your typewriter to the park." Cramer (2015) argues this meme

T. S. Dufva $(\bowtie)$

Department of Art, Aalto University, Espoo, Finland

e-mail: tomi.slottedufva@aalto.fi

(C) The Author(s) 2021

K. Tavin et al. (eds.), Post-Digital, Post-Internet Art and Education, Palgrave Studies in Educational Futures, https://doi.org/10.1007/978-3-030-73770-2_16 
is a fit illustration of post-digitality as it displays the rift between digital and postdigital; where some analogue tools, such as typewriters and film cameras have resurfaced as a compelling option to the digital ones. As such, the post-digital questions the ongoing progress of digital technology, seeking alternatives by reaching to past technologies. The seeking of the past is not to be confused with a refusal of the new, but instead as a revaluation of the usefulness and direction of the digital technologies. Cramer draws an analogue to cars and bicycles: After World War II, the common assumption was that cars are far superior to bicycles regardless of the context. Now, post-car, the evaluation is entirely different, questioning the superiority of cars in many ways (Cramer, 2015). As such, post-digital refers to a perspective that is altered because of the ubiquitous digital processes; it is not a question of progress from pre-digital to digital and further, but a state where digital is complexly intertwined with many common, uncommon, and everyday significant processes and assemblages. This chapter proposes possibilities for art education to explore post-digital worlds. The use of post-digital worlds refers to the complex nature of the post-digital; There is no one post-digital world, but instead, I propose that post-digital creates multiple worlds, or worldings (Anderson \& Harrison, 2010), based on the subject's location, socio-economic status, and much more.

The world saturated with digital technologies is not an equal one. Instead, it could be said to widen the income gap (Morozov, 2014), strengthen the colonial powers (Couldry \& Mejias, 2019), or benefit only a small number of people, often those in charge (Lanier, 2014; Zuboff, 2019), to name just a few challenges. One simple example to show how the digital processes tie into these broad questions is the act of taking photographs. Taking a photo with a smartphone does not only take the picture but records location, time, battery status, altitude, as well as a plethora of other data depending on the smartphone and application used. Furthermore, a photo uploaded to a social media service, a modern analogue to showing a photo album at family get-togethers, is not only a photo displayed to relatives but an analyzable collection of data and metadata, such as identification of people, brands, or even emotions in the picture. All of this is ready to be harvested by the companyor country-providing the service (see, e.g., Dieterring, 2019; Knuutila, 2019; Pariser, 2012; Stöckli et al., 2018). Because of this, the understanding of post-digital might be convoluted as some of the challenges can be seen to delve more around the issues of switching to digital (from 
non-digital) or connecting more closely to broader socio-economic, political, and cultural challenges. Nevertheless, post-digital is a useful concept as it opens a perspective into the digital landscape that is not concentrated on the digitalization per se, but rather deals with the complex issues of the current situation and broadens the discussion for possible and alternative future paths. Fleischer (2009), a Swedish media theorist, writes that post-digital asks how does digital take place, ${ }^{1}$ meaning that the question of post-digital is about how the complex digital processes, or systems, fold and unfold in various spaces.

The switch to digital introduced a new layer into everyday processes in the form of code and digital data. Code enabled the universal digital machine, which can be altered to do almost any job with just updating the code (Petzold, 1999). Digital data, then, enabled a form of universal data; all different bits of information could be transformed into bits and bytes, which then could be collected, manipulated, and analyzed in unforeseen speed and scale (Ceruzzi, 2012). These digital layers, code, and data have been supported by the accelerating improvement and cheapening of the hardware (Ceruzzi, 2012; Gabrys, 2013). Post-digital, in this context, is crucial as it works both as a condition and as a field of inquiry into the complex layers of digital actions, the code, data, and hardware have created. In other words, it looks at how digital structures take place. Hayles (2017) proposes that as the digital processes have increasingly more possibilities to gather information, react to it and make choices, and that we should think of them having expanded cognitive capabilities. These cognitive, non-conscious digital processes then form new kinds of systems through complex assemblages between "well-defined interfaces and communication circuits between sensors, actuators, processors, storage media, and distribution networks, and which include human, biological, technical, and material components" (p. 11). As such postdigital, at least how it is understood here, is always political and cultural; Digital has become ubiquitous, but it takes place very differently in the rural villagers shared smartphone than in a preteens tablet in the so-called first world country. Nevertheless, it still takes place.

The questions of post-digital worlds are broad. Therefore, here the focus is on how art education has a significant opportunity in combining coding, data, hardware, and the post-digital with critical and feminist pedagogies into a broadened and meaningful understanding of the current state of post-digital worlds. In particular, I use Fleischer's (2009) 
term of taking place as an instrument to look at the post-digital landscapes; How does the digital take place? Under which conditions does the place taking happen and, under which terms? Moreover, I take a feminist approach to the issues related with the creative coding and post-digital and loan the concept of compost from Haraway (2016), to embody the unequal situations where the taking place happens and the relational roles of different actors. Haraway uses the concept of compost as an image that articulates life in intricate more-than-human ecologies. Here I propose digital compost as a figuration for complex, more-than-digital situations we find us in post-digital worlds.

The next section aims to open up the theoretical context of creative code, and their relationship to art education, after which I will use three courses taught in Aalto University as an example of the aforementioned approach. I conclude this chapter with a short discussion and explore further research.

\section{Feminist Approaches of the Post-Digital}

Traditionally, digital code is understood as a tool to program digital devices (Ceruzzi, 2012; Petzold, 1999). As such, code is considered as a somewhat neutral tool and coding as a functional skill that enables one to manufacture software. This functional understanding runs dominantly throughout the current discourse on teaching coding in schools, putting weight on coding as a skill for employment in the future (Dufva \& Dufva, 2016; Williamson, 2015). Creative coding, an oxymoron as Knochel \& Patton suggest (2015), takes an alternative approach to coding, focusing on the expressive sides of code instead of the functional. Casey Reas, one of the founders of the popular creative coding framework and software, Processing, calls code a way of thinking, as a humanist activity, not a technical skill (Cangiano, 2016).

In general, creative coding includes a broad collection of tools, coding frameworks and software (Processing, Pure Data, Open Frameworks, Arduino, and so on) as well as multiple contexts of art-making and (sub)cultures (code poetry, live coding, hacker culture, maker culture, free software, and so on). From the art educational context, the shift to focus on expression rather than functionality in coding is considerable as it allows for a more in-depth working between the disciplines and enables new kinds of expression in the digital domain (Ettinger, 1988; Knochel \& Patton, 2015). Moreover, creative coding may enable a more in-depth 
and experiential connection with the digital processes, providing students with both hands-on experiences and theoretical frameworks (Dufva, 2018). In general, the pedagogical model outlined in, for example, Knochel \& Patton's work (2015) and Dufva's work (2018) bears similarities with experiential art understanding (Kolb, 2014; Räsänen, 2000). As such, creative coding demonstrates the importance of teaching postdigital issues within art education as it offers abstract theories, critical discussions, and hands-on activities.

However, in this text, I want to move forward with the art educational approach of creative coding and think creative coding as compost(ing). Whereas creative coding focuses on expression and general critical understanding of the digital, the approach of compost focuses on the myriad of ways of how code takes place. Composted creative coding seeks to queerify $^{2}$ the code; Code is not only functional, political, and emancipatory but a complex folding of them, a variety of virtualities and assemblages that are bound to the subject in diverse ways. I argue that dirtying the often abstract and invisible digital processes with the muddy waters of the human subject, gender and cultures are more important than ever.

Feminist interpretations of the digital are nothing new, starting from Ada Lovelace, the first computer programmer (Petzold, 1999) and Haraway's "Simians, Cyborgs and Women" (1991), feminist theories have significantly contributed into digital debates. Still, the feminist perspectives are not often readily accepted in the programming communities. When Ari Schlesinger, a computing researcher at Georgia Institute of Technology, proposed an idea of feminist programming language (Schlesinger, 2013), she was met with ridicule and chauvinism in the form of a joke programming language in the GitHub ${ }^{3}$ ("r/ProgrammerHumor," 2014; White, 2013). The inequality and lack of diversity is a well-known fact in the digital technology industries (Collins, 2017; Jarrett, 2015) and the situation does not seem to be getting any better (Tassabehji et al., 2020). Although it never has been: D'Ignazio and Klein tell a story of the first women working at NASA, highly educated, being responsible for the majority of the calculations, were despite their crucial role, only called computers, instead of their real names (2020 p. 3).

Bassett, Kember, and O'Riordan (2019) postulate that the role of women in post-digital processes is vexed; They are at the same time overachieving business miracle workers, super-fit housewives taking care of 
children and pleasing the husband while being almost entirely absent from the development of these digital technologies. They call the women's role in the post-digital as cinderella's, highlighting the impossible and even paradoxical role of everyone who is not a wealthy white male. Thinking these issues through creative code as compost(ing), inspired by the intersectional feminist theories, brings forth questions of how and under which circumstances these roles take place; how is the taking placed designed and presented and under with assemblages and virtualities. Paraphrasing Haraway (2016), it matters what codes code and which data creates data. Or even, how do we become with the code, and how do we think with the code? In the approach of creative coding of compost(ing), the hermeneutical spiral of experiential art understanding is questioned: Instead of a hierarchical model, or progress toward a specific direction, learning is envisioned as layered, somewhat simultaneous processes of taking place. The aim of such compost(ing) is to take diverse post-digital worlds into account.

In the next section, I use three courses for university students (two for art education students and another for University-Wide Art Studies (UWAS), ${ }^{4}$ as examples of the approach and its possibilities. The art education course Digitalization and Learning 1 works as an introductory course to digital issues, and the other course, Sustainable design pedagogy and materiality, brings forth immaterial and sustainability issues within the post-digital world. The university-wide course, Creative coding, is a general introduction course to art and code. These three courses are not meant to be presented as empirical proof of the creative coding as composting approach, but rather as examples of how such practices can take place in university education. It is important to note that in regard to feminist theories and post-digital worlds, courses taking place in a wellresourced Nordic country (Finland), and in one of the top art and design universities in the world (Aalto University, School of Arts, Design, and Architecture), can hardly suggest to comprehend all the complex and exclusionary issues within post-digital worlds. The perspective from these courses is inevitably white and Western. However, working within the comprehension of the privileged perspective the courses aim to discuss and work through these complex unequal issues and situate oneself into the post-digital world(s). 


\section{Digital Compost}

As mentioned earlier I am presenting these examples as a compost, tossing post-digital processes in contact with other things and species. However, due to the limited scope of this chapter, I will only highlight a few aspects of this compost. Many other things will be left decomposing. These examples are all simple assignments from the courses and do not require complicated hardware or software. Creative coding as compost(ing), as used in the example classes, is not a model to follow pedantry, but more a kind of a getting hands dirty with the post-digital: It is more like sinking hands into the unknown ground. There are many things: roots, webs, bugs, worms, dirt, and humus. Issues that arise may be so complex that a teacher cannot (and should not) be the all-knowing prophet of wisdom. Instead, the teacher may create a space that gives rise to concepts that allow us "to surround ourselves with the possibilities for being otherwise" (Grosz, 2012, p. 14).

\section{Humus}

How would you signal a picture of a cat, using only sound (no words) to a person that cannot see you? This question works as a starting point in the digitalization and learning 1 -course, the introductory course for the first-year art education students (BA). The course had 16 participants and took place in January 2020 at Aalto University. The assignment was used in the beginning of the course, before a preliminary lecture of the post-digital world, with the aim to give experiential context of the digital processes and to discuss them within this more freeform context, before introducing any theories or frameworks. The experiment in question is called a human fax machine (Bunt \& Ihlein, 2013) and requires only a pen and paper. In the experiment, students form small groups and negotiate their own sound-based fax machine language. Sounds can be made with voice, or it can be clapping, drumming, or something other. Then the group is split between coders and decoders. Coders transmit the picture and decoders draw the picture based on the language created. After each picture, the group can evaluate their results and improve the language.

At the end of the experiment, different groups get to know other groups solutions. The experiment aims to raise awareness on how code is social, political, and cultural; different groups come up with entirely different solutions. Whereas some students create logical matrix kind 
systems of drawing, some create improvisational languages based on the feeling of the voice. The human fax machine works as an introduction; it takes into account multiple aspects of the digital, presenting clear ways the code takes place and is used. It aims to give the idea of the social assemblages inherent in many post-digital processes. It works as the soil of the compost; the dirt, the humus, that makes the invisible digital processes visible, and somewhat graspable. Programming languages are composed within the limitations of the technology available, but within these boundaries they are questions of collective choice, culture, politics, and economy. Moreover, the assignment presents code from a broader perspective than any actual coding framework could do; one does not have to start from the binary logic of digital. As such, it empowers students in thinking that code-and digital processes could be greatly altered.

\section{Care}

In a recent article series, reporter Kashmir Hill tested how one could live without the big five tech giants (Hill, 2019). The results are somewhat predictable - it becomes pretty hard pretty quickly to live a normal life as a reporter working for a website-but the results still portray how we are tied into these vendors in many, often unforeseen, ways. One homework assignment in the UWAS creative coding course, open to all students in Aalto University regardless of their discipline, has been an assignment called "a week in hell," that asks the students to change their digital routines: If one is using Google, try out Duckduckgo, avoid social media for a week, or seek other ways to question your digital surroundings. The results are always impressive: Some students say how it feels worthless to walk because they gave up on wearing a smartwatch that counts their steps. Others feel stress because they imagine all the uncaught Pokémon's passing by while walking. Furthermore, some are already so well-versed of the digital privacy issues that the week makes them go wild and try TikTok, because they write that they have already abandoned Google, do not use Facebook and encrypt their emails. This year the course was offered as a web-based ${ }^{5}$ course and there were 78 students from all over Aalto taking the course, therefore there were lots of different answers and reactions. However, it should be noted that none of the students thought the assignment was easy. 
The "week in hell" highlights the themes of care and questioning. The focus on routine digital processes brings forth the questions of feeling and quality of the digital processes that take place: Why are we using what we are using, and could the digital processes be better? Discussions after the assignment also raise awareness of the inequality and the very different post-digital worlds taking place at the same time. Even though the assignment is very much so-called first-world oriented, the students in the course still often share unique viewpoints and considerations that range from the ecological to gender, and further to political issues. Moreover, the task reveals how the digital and real constantly create and negotiate the post-digital surroundings. Fleischer draws an analogue to how birds take place with their singing and how a motorway nearby takes place by drowning the singing (Fleischer, 2009). After the assignment one student mentioned how she had switched to using Ecosia ${ }^{6}$ search engine instead of Google as it uses only renewable energy and claims to use the income they get from ads to plant trees. This mention lead to a larger discussion of sustainability and the different possibilities of sustainability in the postdigital world(s). Another student claimed that Instagram censors pictures from transgender or overweight people based on their algorithms, which then led into large discussions of gender, body-image and how internet is affecting all that. The assignments and examples portray that awareness and constant care of the post-digital routines are required. Care is, at the same time, personal and complexly universal.

\section{Waste}

Waste is a significant issue in digital technologies. E-waste fills landfills (mostly in so-called third-world countries) and is a major polluter (Gabrys, 2013). It is hard to think of good enough compost that could turn all the e-waste back into raw materials. It is even challenging to comprehend all the raw materials digital devices require. Moreover, some digital processes demand massive amounts of energy. As an example, training machine learning models require a vast amount of computing power and energy (García-Martín et al., 2019). Similarly, recent research revealed that Bitcoin currently uses as much energy as the whole of Switzerland (Baraniuk, 2019). The discussions around the energy and material resource use of digital devices are still novel and underdeveloped. Some companies have aimed for greener and more energy-efficient processes (Greenpeace, 2008; Howard, 2010). However, many problems 
remain. For instance, the origins of some materials are hard to verify. Even Fairphone, a company whose mission is to make sustainable and fair mobile devices have run into troubles on verifying the fairness and sustainability of all of their materials (Garrigou, 2019; Schwa, 2019). With the release of cheap Internet of Things devices that utilize AI, the questions of material and energy use have become even more complicated (Crawford \& Joler, 2018).

To bring forth these issues of materiality and sustainability, the sustainable design pedagogy and materiality-course for BA and MA art education students, includes a task of opening a device. The instructions are simple: find a device that you do not use anymore or is broken, or you are sure you can put together later on, and start opening it. Document the pieces you find, if possible, search for components from the internet. Do not try to open TVs, washing machines, or other devices that use high-voltage. Preferably use only small devices that work on batteries. Local recycling centers are often glad to donate appropriate devices as they are drowning in them. The assignment can generate nervousness in some, as they might be afraid of opening a device, after all, many devices come with warning labels such as "warranty void if opened." Furthermore, some students become stressed about the amount of e-waste they are accumulating. However, opening a device also opens up a new world of the post-digital. It is the part hidden world of seeing inside the devices and owning them, and can be seen to be closely tied to hacker and maker cultures (Fox et al., 2015; Konopasky \& Sheridan, 2015).

One student, for example, opened a TV remote controller. $\mathrm{He}$ documented the opening process, remarking how it was glued to make the opening more difficult. He then found a microchip inside the controller with some text on it and searched the internet with that text. He found the datasheet and company manufacturing the chip. He searched for the company, found its headquarters in Shenzhen, China, one of the world's biggest manufacturing cities for electronics. He then used Google street view to look at the headquarters and surroundings. Finally, he searched for the weather for the place as well as information from Wikipedia. This example shows how opening a digital device can widen the understanding of the material layers in the digital device. Moreover, it offers one journey into the post-digital worlds where we can use the digital to get to know the digital. However, such a journey is a naturally privileged one, as we do not have to work the probable low-income long shifts in the manufacturing plants or breath the polluted air of Shenzhen. 
After the disassembly, the assignment continues with the task to create artwork based on the materials found in the device. Based on the length of the course, this can be a quick impromptu artwork or well-thoughtout hacking process that retains or reuses the devices functionality, such as reprogramming an electronic toy to work differently.

\section{GoIng FurTher}

The idea of digital compost, and the examples of humus, care, and waste aims to describe some straightforward ideas within the approach of creative coding as compost(ing). They are meant as a brief stories of compost(ing), inspired from Haraway's speculative fabulations and string figures (2016), and seek to portray how we become with the post-digital processes. The examples are purposefully simple, to show how talking about post-digital and code taking place does not necessarily require advanced technological skills. More critical is the situated knowledge of what code codes the code and enabling a place for understanding of the various post-digital worlds that exist at the same time. The picture creative coding as compost(ing) aims to portray is that post-digital issues can be played with and tossed around. As stated earlier, this is what I called dirtying the post-digital, or queerifying the post-digital; An active process of critically examining, and possibly even transforming, how the postdigital takes place. Through putting the often transparent and abstract digital processes into compost, creative coding aims to smear them with agendas, biases, and meaning(s). The human fax machines display the cultural, ideological, political, social, and economic questions within the creation of programming languages. The "week in hell" seeks to bring awareness and care to the compost; we need to tend to it; otherwise, it will just start to stink. Lastly, opening the devices can be emancipatory in many ways, but more importantly, it brings forth how complexly digital devices and processes are tied locally and globally.

However, this text offers only a scratch into the surface of the digital compost. More expansive writing would be required to introduce a practical guide into writing code, or using data within this approach of creative coding as compost(ing). Moreover, a more in-depth dive deep into the compost theory would be required to give a profound perspective to that practical guide of creative coding. Furthermore, empirical research on creative coding, or any post-digital art educational activity would be most 
interesting as it would shed more light into the student's comprehension as well as best practices. There are also exciting paths to take within the embodiment and feminist creative coding as well as with STEAM $^{7}$ education. Going further it may be fascinating to consider creative coding from the context of transhackfeminism ("transhackfeminism," 2020), to explore further how post-digital processes work in biodata and how they could decolonize technologies or work as pedagogies of care.

\section{Notes}

1. Äga rum in Swedish, a literal translation would be to own a room, but Fleischer suggests taking place as an English translation.

2. Queerifying refers to the act of translating an action, story, concept or an issue with queer-terms, i.e. adding queer and feminist voices in the story. For instance, Bassett et al. (2019, p. 45) use this in the scope of digital technologies.

3. GitHub is a popular website for developers to discover, share, and build software, www.github.com.

4. University-Wide Art Studies (UWAS) offers all Aalto students and faculty an opportunity to explore art and design based practices and processes beyond disciplinary boundaries. See https://uwas.aalto.fi.

5. Due to the Covid-19.

6. https://www.ecosia.org.

7. STEAM: Science, Technology, Engineering, Arts, Mathematics.

\section{REFERENCES}

Anderson, B., \& Harrison, P. (Eds.) (2010). Taking - place: Non-representational theories and geography. Ashgate.

Bassett, C., Kember, S., \& O’Riordan, K. (2019). Furious: Technological feminism and digital futures. Pluto Press.

Berry, D., Dieter, M., Berry, D. M., \& Dieter, M. (Eds.) (2015). Postdigital aesthetics. Springer.

Berry, D. (2016). The philosophy of software. Springer. https://doi.org/10.1057/ 9780230306479.

Bunt, B., \& Ihlein, L. (2013). The human fax machine experiment. Journal of media arts culture, 10(2), 1-26. https://ro.uow.edu.au/cgi/viewcontent.cgi? article $=2131$ \&context $=$ lhapapers.

Cangiano, S. (2016). Coding as a way of thinking. https://medium.com/pro getto-grafico/coding-as-a-way-of-thinking-interview-with-casey-reas-cbb9ec dbb980. 
Ceruzzi, P. E. (2012). Computing: A concise history. MIT Press.

Collins, K. (2017). Tech is overwhelmingly male and men are just fine with that. https://qz.com/940660/tech-is-overwhelmingly-male-and-menare-just-fine-with-that/.

Couldry, N., \& Mejias, U. A. (2019). The costs of connection. Culture and Economic Life.

Cramer, F. (2015). What is 'post-digital'? In D. Berry \& M. Dieter (Eds.), Postdigital aesthetics (pp. 12-26). Springer.

Crawford, K., \& Joler, V. (2018). Anatomy of an AI system. Retrieved 5. Dec, 2019 from https://anatomyof.ai/.

D’Ignazio, C., \& Klein, L. F. (2020). Data feminism. MIT Press.

Dieterring, A. (2019). Facial recognition, physiognomy, and racism. https://med ium.com/the-sundial-acmrs/facial-recognition-physiognomy-and-racism-ffc $3 \mathrm{~d} 232 \mathrm{a} 352$.

Dufva, T. (2018). Art education in the post-digital era-Experiential construction of knowledge through creative coding. Doctoral dissertation. Aalto Arts Books.

Dufva, T., \& Dufva, M. (2016). Metaphors of code-Structuring and broadening the discussion on teaching children to code. Thinking Skills and Creativity, 22, 97-110. https://doi.org/10.1016/j.tsc.2016.09.004.

Dufva, T., \& Dufva, M. (2019). Grasping the future of the digital society. Futures, 107, 17-28. https://doi.org/10.1016/j.futures.2018.11.001.

Ettinger, L. F. (1988). Art education and computing: Building a perspective. Studies in Art Education, 30(1), 53. https://doi.org/10.2307/1320652.

Fleischer, R. (2009). Det postdigitala manifestet: Hur musik äger rum. Ink Bokförlag.

Fox, S., Ulgado, R. R., \& Rosner, D. (2015). Hacking culture, not devices. The 18th ACM conference, 56-68. doi:https://doi.org/10.1145/2675133.267 5223.

Gabrys, J. (2013). Digital rubbish. University of Michigan Press.

García, E., Rodrigues, C. F., Riley, G., \& Grahn, H. (2019). Estimation of energy consumption in machine learning. Journal of Parallel and Distributed Computing, 134, 75-88. https://doi.org/10.1016/j.jpdc.2019.07.007.

Garrigou, A.-S. (2019). The more people demand ethical products, the more they will be produced globally. https://the-beam.com/technology/the-more-peo ple-demand-ethical-products-the-more-they-will-be-produced-globally/.

Greenpeace. (2008). Greenpeace accomplishments in the U.S., 2000-2008. https://www.greenpeace.org/usa/wp-content/uploads/legacy/Global/usa/ planet3/PDFs/passacantando-timeline.pdf.

Grosz, E. (2012). The future of feminist theory: Dreams for new knowledges? In H. Gunkel, C. Nigianni, \& F. Soderback (Eds.), Undutiful daughters: New directions in feminist thought and practice (pp. 13-22). Palgrave Macmillan.

Haraway, D. (1991). Simians, cyborgs and women. Routledge. 
Haraway, D. (2016). Staying with the trouble: Making kin in the Chthulucene. Duke University Press.

Hayles, N. K. (2017). Unthought. The power of the cognitive nonconscious. University of Chicago Press.

Hayles, N. K. (2019). Keynote. Proceedings from Moral Machines Ethics and Politics of the Digital World. University of Helsinki, Helsinki, Finland.

Hill, K. (2019). I blocked Amazon, Facebook, Google, Microsoft, and Apple. https://gizmodo.com/i-cut-the-big-five-tech-giants-from-my-life-it-was-hel1831304194.

Howard, P. N. (2010). Routledge handbook of internet politics. Taylor \& Francis. Jarrett, K. (2015). Feminism, labour and digital media: The digital housewife. Routledge.

Knochel, A. D., \& Patton, R. M. (2015). If art education then critical digital making: Computational thinking and creative code. Studies in Art Education, $57(1), 21-38$.

Knuutila, A. (2019). How Facebook predicts your politics: Aesthetics and glossy die cut prints. https://rajapinta.co/2019/03/22/how-facebook-predicts-yourpolitics-aesthetics-and-glossy-die-cut-prints/.

Kolb, D. A. (2014). Experiential learning. FT Press.

Konopasky, A., \& Sheridan, K. M. (2015). An experimental study Comparing two educational approaches to making with simple circuits. [Unpublished manuscript]. George Mason University, Department of Education.

Lanier, J. (2014). Who owns the future? Simon and Schuster.

Morozov, E. (2014). To save everything, click here. Public Affairs.

Pariser, E. (2012). The filter bubble. What the internet is hiding from you. Penguin.

Petzold, C. (1999). Code: The hidden language of computer hardware and software. Microsoft Press.

Räsänen, M. (2000). Sillanrakentajat (28). Taideteollinen korkeakoulu.

Sample, I. (2020). What are deepfakes_ And how can you spot them? https://www.theguardian.com/technology/2020/jan/13/what-aredeepfakes-and-how-can-you-spot-them.

Schwa, K. (2019). Fairphone 3: It's hard to make an ethical smartphone. https:// www.fastcompany.com/90395841/its-really-really-hard-to-design-a-smartp hone-that-doesnt-hurt-people-or-the-planet.

Schlesinger, A. (2013). Feminism and programming languages. https://www. hastac.org/blogs/ari-schlesinger/2013/11/26/feminism-and-programminglanguages.

Shabot, S. C., \& Landry, C. (2018). Rethinking feminist phenomenology: Theoretical and applied perspectives. Rowman \& Littlefield.

Stöckli, S., Schulte-Mecklenbeck, M., Borer, S., \& Samson, A. C. (2018). Facial expression analysis with AFFDEX and FACET: A validation study. 
Behavior Research Methods, 50(4), 1446-1460. https://doi.org/10.3758/s13 428-017-0996-1.

Tassabehji, R., Harding, N., Lee, H., \& Dominguez-Pery, C. (2020). From female computers to male computơrs: Or why there are so few women writing algorithms and developing software. Human Relations, 001872672091472,. https://doi.org/10.1177/0018726720914723.

Transhackfeminism. (2020). Pirate.Care.syllabus. https://syllabus.pirate.care/ topic/transhackfeminism/\#transhackfeminism.

Vaccari, C., \& Chadwick, A. (2020). Deepfakes and disinformation: Exploring the impact of Synthetic political video on deception, uncertainty, and trust in news. Social Media + Society, 6(1), 205630512090340. doi:https://doi.org/ $10.1177 / 2056305120903408$.

White, M. (2013). Why I'm not laughing at C Plus Equality. https://blog.mol lywhite.net/why-im-not-laughing-at-c-plus-equality/.

Williamson, B. (2015). Political computational thinking. Critical Policy Studies, 1-20,. https://doi.org/10.1080/19460171.2015.1052003.

Zuboff, S. (2019). The age of surveillance capitalism. Public Affairs.

Open Access This chapter is licensed under the terms of the Creative Commons Attribution 4.0 International License (http://creativecommons.org/licenses/ by $/ 4.0 /)$, which permits use, sharing, adaptation, distribution and reproduction in any medium or format, as long as you give appropriate credit to the original author(s) and the source, provide a link to the Creative Commons license and indicate if changes were made.

The images or other third party material in this chapter are included in the chapter's Creative Commons license, unless indicated otherwise in a credit line to the material. If material is not included in the chapter's Creative Commons license and your intended use is not permitted by statutory regulation or exceeds the permitted use, you will need to obtain permission directly from the copyright holder.

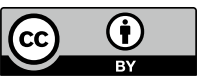

